\title{
Influence of microgravity-induced intervertebral disc degeneration of rats on expression levels of p53/p16 and proinflammatory factors
}

\author{
YANG LI ${ }^{1,2}$, LEI CAO ${ }^{2}$, JUN LI $^{2}$, ZHONGYI SUN ${ }^{2}$, CHAO LIU $^{2}$, \\ HE LIANG $^{2}$, DEGUO WANG ${ }^{2}$ and JIWEI TIAN ${ }^{1}$ \\ ${ }^{1}$ Shanghai General Hospital of Nanjing Medical University, Shanghai 200080; \\ ${ }^{2}$ Central Hospital of Shanghai Songjiang District, Shanghai 201600, P.R. China
}

Received December 19, 2017; Accepted November 8, 2018

DOI: 10.3892/etm.2018.7085

\begin{abstract}
Association of expression levels of tumor suppressor proteins $\mathrm{p} 53$ and $\mathrm{p} 16$ and inflammatory factors in simulated weightlessness with the degree of lumbar disc degeneration of rats was investigated. Magnetic resonance imaging (MRI) examination was performed for rats in control group and experimental group, and the intervertebral disc of rats in both groups was detected and analyzed using hematoxylin and eosin (H\&E) histopathological staining. The mRNA expression levels of proinflammatory factors, interleukin-1 $\beta$ (IL-1 $\beta$ ), IL-6 and tumor necrosis factor- $\alpha$ (TNF- $\alpha$ ) were detected, and p53 and p16 mRNA and protein expression levels were detected. MRI results showed significant intervertebral disc injury in experimental group. Results of $\mathrm{H} \& \mathrm{E}$ staining revealed that the intervertebral disc injury in experimental group was more serious with obvious signs of degeneration than that in control group. The mRNA expression levels of inflammatory factors (IL-1 $1 \beta$, IL- 6 and TNF- $\alpha$ ) in rats in experimental group were significantly increased compared with those in control group, indicating that the degree of lumbar disc degeneration of rats in simulated weightlessness is closely related to the inflammatory factors. RT-PCR and western blotting proved that both p53 and p16 mRNA and protein expression levels in experimental group were obviously increased. Results of t-test manifested that there were statistically significant differences in p53 and p16 expression levels between control group and experimental group $(\mathrm{P}<0.01)$. The abnormal expression levels of p53 and p16 genes have close association with the degree of lumbar disc degeneration of rats in simulated weightlessness,
\end{abstract}

Correspondence to: Dr Jiwei Tian, Shanghai General Hospital of Nanjing Medical University, 100 Haining Road, Hongkou, Shanghai 200080, P.R. China

E-mail: m18721737863@163.com

Key words: simulated weightlessness, p53, p16, lumbar disc degeneration, inflammatory factors and the lumbar disc degeneration is also closely related to the increased expression levels of inflammatory factors.

\section{Introduction}

With the continuous progress in space exploration technology, astronauts have to face the harsh physical environment and serious physiological changes in short-term and long-term space missions. The major physiological changes include the loss of bone mass, muscle atrophy, arrhythmia, cognitive disorders and loss of sense of direction (1-5). Moreover, severe lumbago, especially low back pain, will occur in astronauts during or after space missions, which also increases the risk of protrusion of lumbar intervertebral disc after flight $(6,7)$. In addition, the intervertebral disc degeneration is also found in animals participating in the space flight test (8).

Lumbar disc degeneration is the leading cause of low back pain. Intervertebral disc degeneration is a complex process, and some scholars have proposed the concept of intervertebral disc microenvironment in recent years: The interaction among intervertebral disc cells, extracellular matrix and biomechanics maintain the balance of intervertebral disc microenvironment. Intervertebral disc degeneration is the result of imbalance of intervertebral disc microenvironment, in which the intervertebral disc cell senescence may be one of the most important initiators (9).

Studies have found that the cell senescence process is mainly realized through activating the $\mathrm{p} 53-\mathrm{p} 21-\mathrm{Rb}$ pathway and p16-Rb pathway $(10,11)$. p53 is the first tumor suppressor gene discovered, which is involved in a variety of cell biological processes, including cell proliferation, senescence and death $(12,13)$. It was found that p53 has significantly high expression in degenerative intervertebral disc tissues (14). p16 gene is another tumor suppressor gene involved in the regulation of cell cycle and negative regulation of cell proliferation and division. Studies have demonstrated that p16 is expressed in degenerative intervertebral disc tissues, and the number of p16-positive cells is positively correlated with the grade of intervertebral disc degeneration (15). However, the roles of p16 and p53 in microgravity-induced lumbar disc degeneration remain unclear (16). 
In the process of intervertebral disc degeneration caused by senescence and biological stress, the expression levels of pro-inflammatory factors, such as interleukin-1 $\beta$ (IL-1 $\beta$ ), IL-6 and tumor necrosis factor- $\alpha(\mathrm{TNF}-\alpha)$, are significantly increased (17), leading to severe inflammatory response $(18,19)$. In microgravity-induced lumbar disc degeneration, the expression levels of these pro-inflammatory factors deserve to be explored.

In this study, Sprague-Dawley (SD) rats were used and randomly divided into control group and experimental group. The degeneration model was established via simulated weightlessness using the tail-suspension method, the messenger ribonucleic acid (mRNA) levels of p53, p16, IL-1 $\beta$, IL-6 and TNF- $\alpha$ were detected via magnetic resonance imaging (MRI) examination, hematoxylin and eosin $(\mathrm{H} \& \mathrm{E})$ histopathological staining and reverse transcription-polymerase chain reaction (RT-PCR), and p53 and p16 protein levels were detected via western blotting, so as to provide an experimental basis for the preliminary discussion on microgravity-induced intervertebral disc degeneration.

\section{Materials and methods}

Laboratory animals and grouping. A total of 24 healthy male specific pathogen-free (SPF) SD rats weighing $(300 \pm 30 \mathrm{~g}$, 12 weeks old) were purchased from Animal Core Facility of Nanjing Medical University. The mice were kept in an SPF animal facility at the Laboratory of Nanjing Medical University [health license no.: SYXK (Su) 2015-0009]. The rats were caged separately in a room and the housing conditions wereconstant temperature of $21^{\circ} \mathrm{C}$ and $12 / 12 \mathrm{~h}$ diurnal cycle. The $24 \mathrm{SD}$ rats were randomly divided into experimental group and control group of 12 rats each. In experimental group, the model was established via simulated weightlessness using the tail-suspension method (tail suspension for 8 weeks for each group), and rats were fed separately. In control group, the tail was not suspended, and rats were also fed separately. Six SD rats were randomly selected from each group and anesthetized using 3\% isoflurane gas mixed with air in an air tight anesthesia chamber at 8 weeks. To simulate the weightlessness, the tail of rats in experimental group was suspended to get the posterior limbs off the ground according to articles published previously (20). A previous study has proven that simulated weightlessness accelerates the intervertebral disc degeneration (21). In short, the tail was fixed with tape first, and then linked to the top of cage through the chain. There was a small sheave at the junction of the chain and the top of cage, so that the rat could move freely along the chain. The posterior limbs were approximately $0.5 \mathrm{~cm}$ above the ground with the head downwards at $30^{\circ}$. Finally, all rats in experimental group were euthanized under using 3\% isoflurane gas mixed with air. This study was approved by the Animal Ethics Committee of Shanghai General Hospital of Nanjing Medical University Animal Center (Shanghai, China).

Main reagents. Bicinchoninic acid (BCA) protein quantification kit (C503051, Sangon Biotech, Shanghai, China), UNIQ-10 Column TRIzol Total RNA Isolation kit (B511321, Sangon Biotech), M-MuLV One-step RT-PCR kit (B532431, Sangon Biotech), GAPDH (D4C6R) mouse mAb
Table I. RT-PCR primer sequences of IL-1 $\beta$, IL-6, TNF- $\alpha$ and $\beta$-actin mRNA.

\begin{tabular}{ll}
\hline Gene name & \multicolumn{1}{c}{ Primer sequence } \\
\hline IL-1 $\beta$ & 5'-3': CCCTGAACTCAACTGTGAAATAGCA \\
& 3'-5': CCCAAGTCAAGGGCTTGGAA \\
IL-6 & 5'-3': ATTGTATGAACAGCGATGATGCAC \\
& 3'-5': CCAGGTAGAAACGGAACTCCAGA \\
TNF- $\alpha$ & 5'-3': TCAGTTCCATGGCCCAGAC \\
& 3'-5': GTTGTCTTTGAGATCCATGCCATT \\
p53 & 5'-3': GGACGACAGGCAGACTTTC \\
& 3'-5': CAAGGCCTCACAGCTCTC \\
p16 & 5'-3': CTCACCATGGATGATGATATCGC \\
& 3'-5': AGGAATCCTTCTGACCCATGC \\
$\beta$-actin & 5'-3': GAGCCGGGAAATCGTGCGT \\
& 3'-5': GGAAGGAAGGCTGGAAGATG \\
\hline
\end{tabular}

Table II. MRI results in control group and experimental group.

\begin{tabular}{lcccc}
\hline Group & Grade 1 & Grade 2 & Grade 3 & Grade 4 \\
\hline Control & 12 & 0 & 0 & 0 \\
Experimental & 0 & 1 & 3 & 8 \\
\hline
\end{tabular}

(cat. no. 97166, Cell Signaling Technology, Inc., Danvers, MA, USA), p53 (1C12) mouse mAb (cat. no. 2524, Cell Signaling Technology, Inc.), anti-p16 (Ab-1) mouse mAb (DCS-50.1/H4) (cat. no. NA29-100UG, Chemicon; EMD Millipore, Billerica, MA, USA) and anti-mouse IgG, HRP-linked antibody (cat. no. 7076, Cell Signaling Technology, Inc.).

MRI examination. Rats in experimental group and control group were taken, anesthetized and fixed on the carton board. This was followed by MRI examination. Grading evaluation was performed according to the criteria of MRI Classification of Disc Degeneration, Pfirrmann et al (22): Grade 1: there is partial loss and multiple fractures in the nucleus pulposus, grade 2: The nucleus pulposus cells are reduced, and the compensatory enlargement of nucleus can be seen at the junction with the inner annulus fibrosus, grade 3: The nucleus pulposus cells are significantly reduced, and the cartilaginous metaplasia of nucleus pulposus cells is obvious, and grade 4: Nucleus pulposus cells are rare, and more interim cells can be seen.

$H \& E$ staining. The lumbar disc tissues in control group and experimental group were taken, fixed in $10 \%$ formalin $\left(20^{\circ} \mathrm{C}, 24 \mathrm{~h}\right)$, dehydrated, embedded into paraffin and sliced into $5 \mu \mathrm{m}$-thick sections, followed by H\&E staining. Briefly, slides were washed using distilled $\mathrm{H}_{2} \mathrm{O}$ and then stained with Hematoxylin-Eosin staining kit (cat. no. E607318, Sangon Biotech) $\left(20^{\circ} \mathrm{C}, 5-10 \mathrm{~min}\right)$ according to the manufacturer's protocol. After that, sections in both groups were sealed, and 


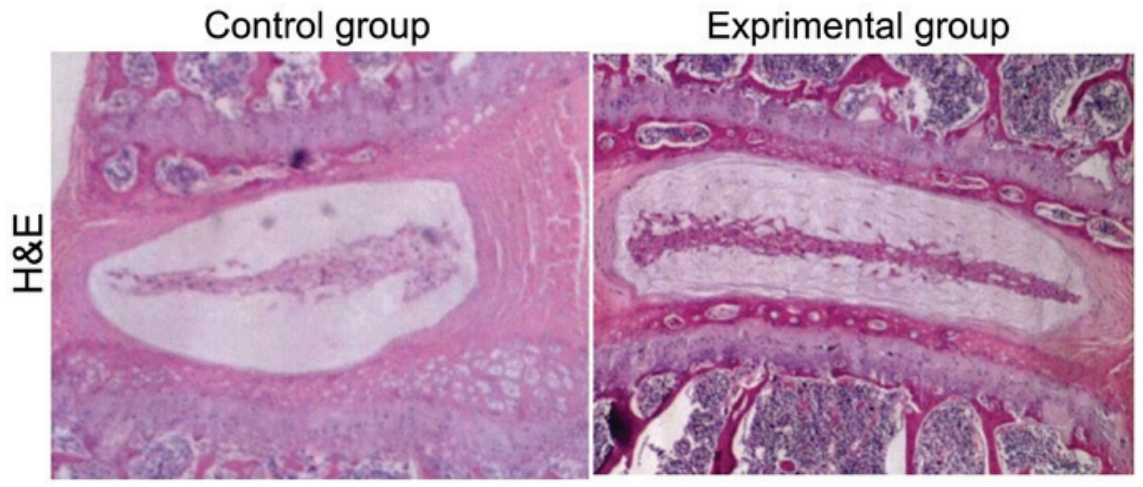

Figure 1. Results of H\&E staining of intervertebral disc in control group and experimental group (x200). Compared with control group, in the experimental group, the morphology of the cartilage showed disorganization and narrowing of intervertebral space.

the pathological differences in lumbar disc tissues between the two groups were observed and photographed for analysis under an upright light microscope (IX51 Olympus Corporation, Tokyo, Japan).

RT-PCR analysis. The lumbar disc tissues in control group and experimental group were taken, added with $1 \mathrm{ml} \mathrm{TRIzol,}$ cut into pieces and fully ground to homogenate. The samples were completely lysed using Tissue Total Protein Lysis Buffer (cat. no. C500028, Sangon Biotech) at room temperature for $5 \mathrm{~min}$ and centrifuged at $12,000 \mathrm{xg}$ and $4^{\circ} \mathrm{C}$ for $5 \mathrm{~min}$. Then the supernatant was taken carefully, added with chloroform and mixed evenly, followed by standing at room temperature for $5 \mathrm{~min}$ and centrifugation at $12,000 \mathrm{x} \mathrm{g}$ and $4^{\circ} \mathrm{C}$ for $15 \mathrm{~min}$. The supernatant was carefully taken and added with the same volume of isopropanol, followed by standing at room temperature for $10 \mathrm{~min}$ and centrifugation at 12,000 $\mathrm{x} \mathrm{g}$ and $4^{\circ} \mathrm{C}$ for $10 \mathrm{~min}$. The precipitate was retained, added with $75 \%$ ethanol and mixed evenly to wash the RNA precipitate. Finally, RNase-free water was added to completely dissolve the precipitate. The optical density $(\mathrm{OD})_{260} / \mathrm{OD}_{280}$ ratio was determined and the RNA concentration was detected. The stepwise amplification was performed according to the instructions and the primer sequence templates shown in Table I, and the RT-PCR was performed for the reaction products.

Western blot analysis. The lumbar disc tissues in control group and experimental group were taken and washed twice with ice cold normal saline. According to instructions of the whole protein extraction kit (cat. no. C500028, Sangon Biotech), tissues were added with lysis solution and homogenized for 1 min using a tissue homogenizer, followed by centrifugation at $12,000 \mathrm{x} \mathrm{g}$ and $4^{\circ} \mathrm{C}$ for $10 \mathrm{~min}$. The supernatant was collected as the total protein of tissues. The protein concentration was determined using the BCA protein concentration assay kit (C503051, Sangon Biotech). Total protein $(20 \mu \mathrm{g})$ was separated via a $10 \%$ SDS-PAGE gel and transferred to PVDF membranes (Sangon Biotech). The PVDF membranes were blocked with $1 \%$ bovine serum albumin (BSA, cat. no. A604481, Sangon Biotech) dissolved in TBST for $1 \mathrm{~h}$ at room temperature and then incubated with primary antibodies for $1 \mathrm{~h}$ at room temperature or overnight at $4^{\circ} \mathrm{C}$. The primary antibodies used were as follows: p53 (1C12) mouse mAb, anti-p16 (Ab-1) mouse mAb (DCS-50.1/H4) and GAPDH (D4C6R) mouse $\mathrm{mAb}$. After washing with TBST 3 times, anti-mouse IgG, HRP-linked antibody as secondary antibody was added and was detected using an EasyBlot ECL kit (C506668, Sangon Biotech). Immunoreactivity of p53 or p16 was quantified using ImageJ software (version 1.45) [National Institutes of Health (NIH), Rockville, MD, USA].

Statistical analysis. The experimental data are expressed as mean \pm standard error of mean (mean \pm SEM), and SPSS 17.0 software (SPSS, Inc., Chicago, IL, USA) was used for the statistical analysis of experimental results. The difference between two groups was calculated by $\mathrm{t}$-test. $\mathrm{P}<0.05$ was considered to indicate a statistically significant difference.

\section{Results}

MRI examination results. MRI examination was performed for rats in control group and experimental group. Results revealed that the intervertebral disc in control group was normal, while there was significant intervertebral disc injury in experimental group (Table II).

$H \& E$ staining results. Compared with those in control group, the L4/5 and L5/6 intervertebral discs had obvious signs of degeneration after intervertebral disc injury with disc height loss, nucleus pulposus structure disorder in annulus fibrosus and inflammatory cell infiltration in experimental group (Fig. 1).

$R T-P C R$ results of inflammatory factors. The total RNA was extracted from the intervertebral disc tissue samples in experimental group and control group and detected via RT-PCR. Results showed that the mRNA expression levels of inflammatory factors (IL-1 $\beta$, IL- 6 and TNF- $\alpha$ ) in experimental group were significantly increased compared with those in control group, indicating that the lumbar disc degeneration of rats in simulated weightlessness is closely related to inflammation (Fig. 2).

$R T-P C R$ results of p53 and p16 $m R N A$. RT-PCR results manifested that compared with those in control group, p53 and p16 mRNA levels in intervertebral disc tissues in experimental group were obviously increased, suggesting that p53 and p16 

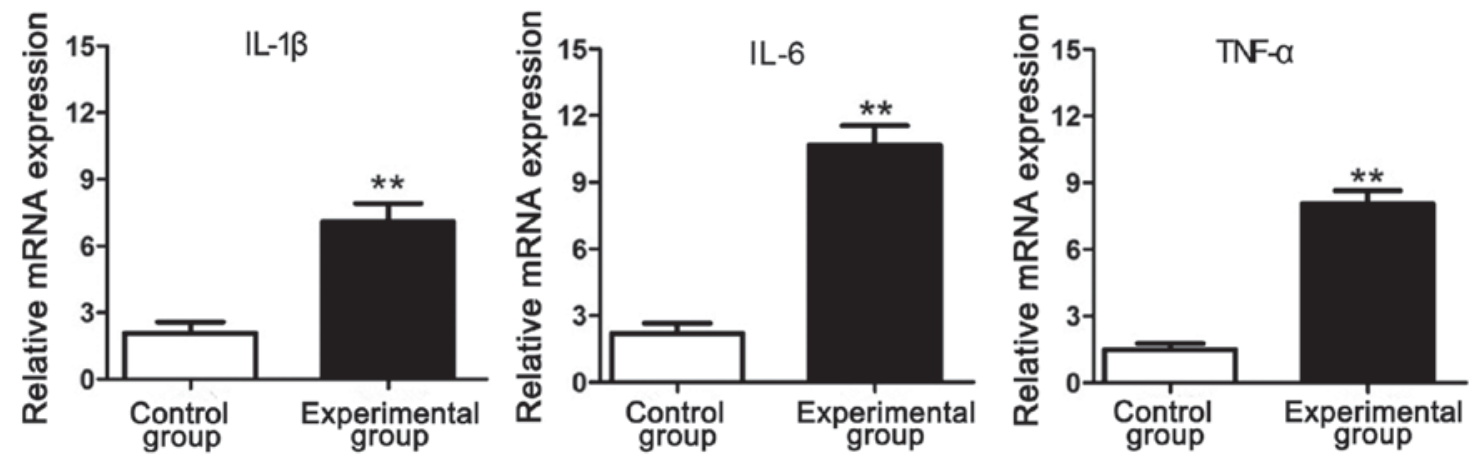

Figure 2. mRNA expression levels of IL-1 $\beta$, IL-6 and TNF- $\alpha$ in intervertebral disc tissues in experimental group and control group. The values are the mean $\pm \mathrm{SD} .{ }^{* *} \mathrm{P}<0.01$ and vs. control group.
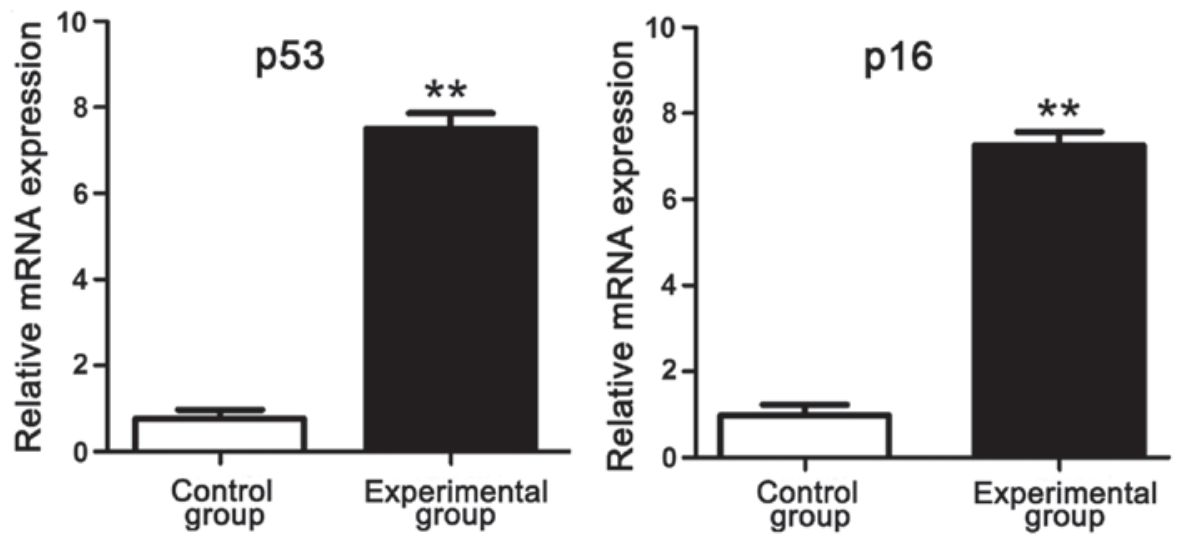

Figure 3. p53 and p16 mRNA expression levels in intervertebral disc tissues in experimental group and control group. ${ }^{* *} \mathrm{P}<0.01$ vs. control group.

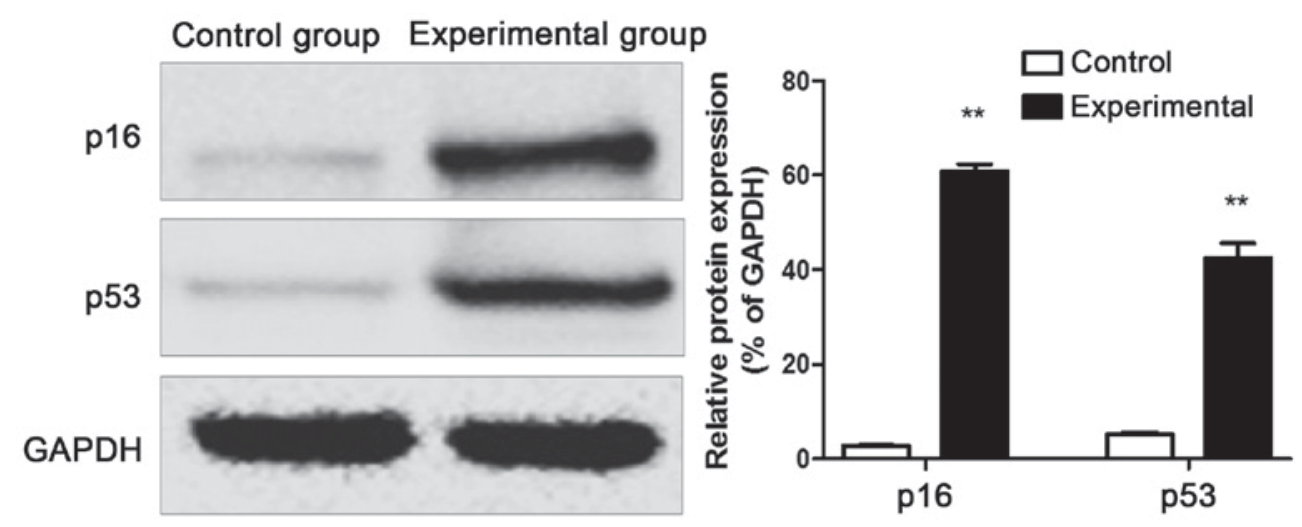

Figure 4. $\mathrm{p} 53$ and p16 protein expression levels in intervertebral disc tissues in experimental group and control group. The values are the mean $\pm \mathrm{SD}$. ${ }^{* *} \mathrm{P}<0.01$ and vs. control group.

genes have an association with the degree of lumbar disc degeneration of rats in simulated weightlessness (Fig. 3).

Western blot results of $p 53$ and p16 proteins. The protein was extracted from the intervertebral disc tissue samples of rats in control group and experimental group, and western blotting results revealed that the p53 and p16 protein expression levels in intervertebral disc tissues of rats in experimental group were remarkably increased compared with those in control group (Fig. 4).

\section{Discussion}

It is reported that lumbago occurs in more than $50 \%$ of astronauts during or after space missions $(8,23)$. Although there is no definite evidence proving that intervertebral disc degeneration is the cause of lumbago in astronauts currently, it is a major cause of low back pain. On the contrary to the sustained stable pressure on intervertebral disc under the standard gravity on the earth, the compressive force against intervertebral disc under weightless environment in the 
space flight significantly declines. In addition, the decline in the hydrostatic pressure on intervertebral disc cells under the weightless condition is considered as the core link in the pathophysiology of intervertebral disc degeneration of astronauts (24). The latest research shows that intervertebral disc degeneration is a constantly developing vicious circle. The homeostasis of intervertebral disc microenvironment is the result of interaction among intervertebral disc cells, extracellular matrix and biomechanics in intervertebral disc. If such a homeostasis is broken, intervertebral disc cells will stop secreting proteoglycan and extracellular matrix components will be changed. Due to the water-gathering effect of proteoglycan, the hydrostatic pressure in intervertebral disc will be reduced, while the shear force will be increased. Such biomechanical changes will further affect intervertebral disc cells, so that they will secrete less proteoglycan. Finally, the vicious circle is formed, and intervertebral disc degeneration will develop constantly (9). It can be seen that the decline in hydrostatic pressure in the intervertebral disc affects the extracellular matrix through affecting intervertebral disc cells under the weightless condition, ultimately breaking the homeostasis of intervertebral disc microenvironment and accelerating the intervertebral disc degeneration. The above results are consistent with those in this experiment that the number and grade of intervertebral disc degeneration in experimental group were significantly larger and higher than those in control group.

Intervertebral disc degeneration has been studied using different animal models in a large number of literature in recent years. Jin et al reported that the culture of intervertebral disc tissues in vitro under simulated weightlessness accelerates the intervertebral disc degeneration (21). However, it is argued that the microenvironment of intervertebral disc in vitro has been destroyed, and whether intervertebral disc degeneration is caused by simulated weightlessness cannot be determined. Therefore, the live rats were fed under simulated weightlessness to study the pathophysiological process of intervertebral disc degeneration in this experiment.

It was found in this study that the p53 and p16 mRNA levels in intervertebral disc tissues of rats in experimental group were significantly increased, and the p53 and p16 protein expression levels were also obviously increased. The molecular mechanism of cell senescence in intervertebral disc degeneration includes two parts. The p53-p21-Rb pathway and $\mathrm{p} 16-\mathrm{Rb}$ pathway play important roles in cell cycle arrest. In telomere damage and DNA damage response, the $\mathrm{p} 53-\mathrm{p} 21-\mathrm{Rb}$ pathway is generally activated, leading to replicative senescence $(13,25)$. p53, as a tumor suppressor gene, is involved in various cell biological processes, including cell proliferation, senescence and death. p53 responds to telomere shortening or DNA damage, and initiates the irreversible cell cycle arrest $(26,27)$. Some experiments reveal that the expression levels of p53, p21 and Rb in senescent nucleus pulposus cells in degenerative nucleus pulposus tissue samples are increased accompanied by telomere shortening and reduced telomerase activity (28). With the extension of culture cycle of nucleus pulposus cells, the p53-p21-Rb pathway is activated in human nucleus pulposus cells, leading to the replicative senescence of intervertebral disc cells (29). At the same time, the 553 expression is significantly up-regulated in senescent annulus fibrosus cells in degenerative intervertebral disc tissue samples (14). According to the latest research, the ATMChk2p53-p21- Rb pathway is activated in the oxidative stress of human nucleus pulposus cells. Unlike the p53-dependent pathway, the non-p53-dependent pathway, p16 pathway, is generally activated by various stimuli, especially oxidative stress, which leads to stress-induced premature senescence (SIPS). p16, as an inhibitor of CDK4 and CDK6, blocks the cell cycle progression when activated by oxidative stress $(30,31)$. Previous studies have found that the p16 gene expression is increased in senescent nucleus pulposus cells in degenerative intervertebral disc tissues $(15,28,32)$, and the number of p16-positive cells is correlated with the grade of intervertebral disc degeneration (15). The p16-Rb pathway is also activated in intervertebral disc cells with the extension of culture cycle, which is consistent with the p53-p21-Rb pathway (29). It has been found in recent studies that the p16-Rb pathway mediates the high glucose-induced senescence of intervertebral disc cells. The aggregation of high glucose produces excessive reactive oxygen species through damaging the mitochondria, so that the p16-Rb pathway is activated and induces SIPS in intervertebral disc cells (33-35). In summary, the senescence of intervertebral disc cells is mainly mediated by the p53-p21-Rb pathway and p16-Rb pathway.

In this study, RT-PCR results showed that the mRNA levels of inflammatory factors (IL- $1 \beta$, IL-6 and TNF- $\alpha$ ) in experimental group were significantly increased compared with those in control group. According to previous studies, senescent nucleus pulposus cells may change the secretion mode to alter the intervertebral disc microenvironment $(13,36)$. In the intervertebral disc, these cells reduce the production of extracellular matrix and enhance the degradation of extracellular matrix. In addition, senescent intervertebral disc cells secrete pro-inflammatory factors (IL- $1 \beta$, IL- 6 and TNF- $\alpha$ ), all of which may accelerate the senescence of adjacent intervertebral disc cells and promote the autoimmune cell infiltration, thereby strengthening the inflammatory response of nucleus pulposus cells in degenerative intervertebral disc $(17,25,36,37)$. In recent years, increasingly more studies have demonstrated that the secretion level of cytokines in the body can be significantly changed in simulated weightlessness, and cytokines exert an efficient regulatory effect in local tissues mainly in autocrine and paracrine manner $(38,39)$. Jin et al found using H\&E staining that degeneration occurs in intervertebral disc tissues of rats cultured under simulated weightlessness, and the expression of MMP-3 and apoptosis of nucleus pulposus cells are increased (21).

In this study, 24 male SD rats were selected and randomly divided into control group and experimental group. The model of lumbar disc degeneration was established via simulated weightlessness in experimental group. MRI examination was performed for rats in control group and experimental group to observe the lumbar intervertebral disc. MRI results showed that the lumbar intervertebral disc of rats in control group was normal, while there was significant intervertebral disc injury in experimental group. The intervertebral disc was detected and analyzed in both groups via H\&E histopathological staining, and it was found that there were obvious signs of degeneration in the intervertebral disc in the experimental group. Moreover, the expression levels of inflammatory factors in both groups 
were detected via RT-PCR, and results manifested that the expression levels of IL-1 $\beta$, IL- 6 and TNF- $\alpha$ in experimental group were significantly increased compared with those in control group. Besides, RT-PCR and western blotting proved that both p53 and p16 mRNA and protein expression levels in experimental group were obviously increased. To sum up, the abnormal expression levels of p53 and p16 genes are closely related to the lumbar disc degeneration in rats in simulated weightlessness, which may lead to the high expression levels of inflammatory factors. This experiment provides a live model for further study on the mechanism of intervertebral disc cell senescence in intervertebral disc degeneration, and lays a foundation for further study on human intervertebral disc degeneration. In the future, more experiments are needed to deeply study the mechanism of cell senescence in intervertebral disc degeneration.

\section{Acknowledgements}

Not applicable.

\section{Funding}

No funding was received.

\section{Availability of data and materials}

All data generated or analyzed during this study are included in this published article.

\section{Authors' contributions}

YL wrote the manuscript. YL and LC were responsible for PCR. JL and ZS analysed and interpreted MRI result. HL and DW contributed to western blot analysis. CL and JT helped with HE staining and statistical analysis. All authors read and approved the final manuscript.

\section{Ethics approval and consent to participate}

This study was approved by the Animal Ethics Committee of Shanghai General Hospital of Nanjing Medical University Animal Center (Shanghai, China).

\section{Patient consent for publication}

Not applicable.

\section{Competing interests}

The authors declare no competing interests.

\section{References}

1. Morey ER and Baylink DJ: Inhibition of bone formation during space flight. Science 201: 1138-1141, 1978.

2. Vico L, Collet P, Guignandon A, Lafage-Proust MH, Thomas T, Rehaillia $\mathrm{M}$ and Alexandre C: Effects of long-term microgravity exposure on cancellous and cortical weight-bearing bones of cosmonauts. Lancet 355: 1607-1611, 2000.

3. Hargens AR and Watenpaugh DE: Cardiovascular adaptation to spaceflight. Med Sci Sports Exerc 28: 977-982, 1996.
4. Vico L, Novikov VE, Very JM, Chappard D and Alexandre C: Effects of a 40 day tail-suspension on rat weight-bearing bones. Physiologist 33 (Suppl 1): S96-S97, 1990.

5. Globus RK, Bikle DD, Halloran B and Morey-Holton E: Skeletal response to dietary calcium in a rat model simulating weightlessness. J Bone Miner Res 1: 191-197, 1986.

6. Sayson JV and Hargens AR: Pathophysiology of low back pain during exposure to microgravity. Aviat Space Environ Med 79: 365-373, 2008.

7. Johnston SL, Campbell MR, Scheuring R and Feiveson AH: Risk of herniated nucleus pulposus among U.S. astronauts. Aviat Space Environ Med 81: 566-574, 2010.

8. Földes I, Kern M, Szilágyi T and Oganov VS: Histology and histochemistry of intervertebral discs of rats participated in spaceflight. Acta Biol Hung 47: 145-156, 1996.

9. Vergroesen PP, Kingma I, Emanuel KS, Hoogendoorn RJ, Welting TJ, van Royen BJ, van Dieën JH and Smit TH: Mechanics and biology in intervertebral disc degeneration: A vicious circle. Osteoarthritis Cartilage 23: 1057-1070, 2015.

10. Webley K, Bond JA, Jones CJ, Blaydes JP, Craig A, Hupp T and Wynford-Thomas D: Posttranslational modifications of p53 in replicative senescence overlapping but distinct from those induced by DNA damage. Mol Cell Biol 20: 2803-2808, 2000.

11. Schmitt CA, Fridman JS, Yang M, Lee S, Baranov E, Hoffman RM and Lowe SW: A senescence program controlled by $\mathrm{p} 53$ and p16INK4a contributes to the outcome of cancer therapy. Cell 109: 335-346, 2002.

12. Toussaint O, Medrano EE and von Zglinicki T: Cellular and molecular mechanisms of stress-induced premature senescence (SIPS) of human diploid fibroblasts and melanocytes. Exp Gerontol 35: 927-945, 2000.

13. Ben-Porath I and Weinberg RA: The signals and pathways activating cellular senescence. Int J Biochem Cell Biol 37: 961-976, 2005.

14. Gruber HE, Watts JA, Hoelscher GL, Bethea SF, Ingram JA, Zinchenko NS and Hanley EN Jr: Mitochondrial gene expression in the human annulus: In vivo data from annulus cells and selectively harvested senescent annulus cells. Spine J 11: 782-791, 2011.

15. Le Maitre CL, Freemont AJ and Hoyland JA: Accelerated cellular senescence in degenerate intervertebral discs: A possible role in the pathogenesis of intervertebral disc degeneration. Arthritis Res Ther 9: R45, 2007.

16. Gruber HE, Ingram JA, Norton HJ and Hanley EN Jr: Senescence in cells of the aging and degenerating intervertebral disc: Immunolocalization of senescence-associated beta-galactosidase in human and sand rat discs. Spine 32: 321-327, 2007.

17. Risbud MV and Shapiro IM: Role of cytokines in intervertebral disc degeneration: Pain and disc content. Nat Rev Rheumatol 10: 44-56, 2014.

18. Acosta JC, O'loghlen A, Banito A, Guijarro MV, Augert A, Raguz S, Fumagalli M, Da Costa M, Brown C, Popov N, et al: Chemokine signaling via the $\mathrm{CXCR} 2$ receptor reinforces senescence. Cell 133: 1006-1018, 2008.

19. Acosta JC, Banito A, Wuestefeld T, Georgilis A, Janich P, Morton JP, Athineos D, Kang TW, Lasitschka F, Andrulis M, et al: A complex secretory program orchestrated by the inflammasome controls paracrine senescence. Nat Cell Biol 15: 978-990, 2013.

20. Zhang R, Ran HH, Cai LL, Zhu L, Sun JF, Peng L, Liu XJ, Zhang LN, Fang Z, Fan YY, et al: Simulated microgravityinduced mitochondrial dysfunction in rat cerebral arteries. FASEB J 28: 2715-2724, 2014.

21. Jin L, Feng G, Reames DL, Shimer AL, Shen FH and Li X: The effects of simulated microgravity on intervertebral disc degeneration. Spine J 13: 235-242, 2013.

22. Pfirrmann CW, Metzdorf A, Zanetti M, Hodler J and Boos N: Magnetic resonance classification of lumbar intervertebral disc degeneration. Spine (Phila Pa 1976) 26: 1873-1878, 2001.

23. Wing PC, Tsang IK, Susak L, Gagnon F, Gagnon R and Potts JE: Back pain and spinal changes in microgravity. Orthop Clin North Am 22: 255-262, 1991.

24. Hutton WC, Elmer WA, Boden SD, Hyon S, Toribatake Y, Tomita $\mathrm{K}$ and Hair GA: The effect of hydrostatic pressure on intervertebral disc metabolism. Spine 24: 1507-1515, 1999.

25. Muller M: Cellular senescence: Molecular mechanisms, in vivo significance, and redox considerations. Antioxid Redox Signal 11: 59-98, 2009.

26. Gire V, Roux P, Wynford-Thomas D, Brondello JM and Dulic V: DNA damage checkpoint kinase Chk2 triggers replicative senescence. EMBO J 23: 2554-2563, 2004. 
27. Herbig U, Jobling WA, Chen BP, Chen DJ and Sedivy JM: Telomere shortening triggers senescence of human cells through a pathway involving ATM, p53, and p21(CIP1), but not p16(INK4a). Mol Cell 14: 501-513, 2004.

28. Kim KW, Chung HN, Ha KY, Lee JS and Kim YY: Senescence mechanisms of nucleus pulposus chondrocytes in human intervertebral discs. Spine J 9: 658-666, 2009.

29. Jeong SW, Lee JS and Kim KW: In vitro lifespan and senescence mechanisms of human nucleus pulposus chondrocytes. Spine J 14: 499-504, 2014.

30. Itahana K, Zou Y, Itahana Y, Martinez JL, Beausejour C, Jacobs JJ, Van Lohuizen M, Band V, Campisi J and Dimri GP: Control of the replicative life span of human fibroblasts by p16 and the polycomb protein Bmi-1. Mol Cell Biol 23: 389-401, 2003.

31. Ressler S, Bartkova J, Niederegger H, Bartek J, ScharffetterKochanek K, Jansen-Dürr P and Wlaschek M: pl6INK4A is a robust in vivo biomarker of cellular aging in human skin. Aging Cell 5: 379-389, 2006

32. Heathfield SK, Le Maitre CL and Hoyland JA: Caveolin-1 expression and stress-induced premature senescence in human intervertebral disc degeneration. Arthritis Res Ther 10: R87, 2008.

33. Park JS, Park JB, Park IJ and Park EY: Accelerated premature stress-induced senescence of young annulus fibrosus cells of rats by high glucose-induced oxidative stress. Int Orthop 38: 1311-1320, 2014.
34. Kong JG, Park JB, Lee D and Park EY: Effect of high glucose on stress-induced senescence of nucleus pulposus cells of adult rats. Asian Spine J 9: 155-161, 2015.

35. Park JB, Byun CH and Park EY: Rat notochordal cells undergo premature stress-induced senescence by high glucose. Asian Spine J 9: 495-502, 2015.

36. van Deursen JM: The role of senescent cells in ageing. Nature 509: 439-446, 2014

37. Muñoz-Espín D and Serrano M: Cellular senescence: From physiology to pathology. Nat Rev Mol Cell Biol 15: 482-496, 2014.

38. Han C, Jiang C, Yu C and Shen H: Differentiation of transforming growth factor $\beta 1$-induced mesenchymal stem cells into nucleus pulposus-like cells under simulated microgravity conditions. Cell Mol Biol (Noisy-le-grand) 61: 50-55, 2015.

39. Luo W, Xiong W, Qiu M, Lv Y, Li Y and Li F: Differentiation of mesenchymal stem cells towards a nucleus pulposus-like phenotype utilizing simulated microgravity In vitro. J Huazhong Univ Sci Technolog Med Sci 31: 199, 2011.

This work is licensed under a Creative Commons Attribution-NonCommercial-NoDerivatives 4.0 International (CC BY-NC-ND 4.0) License. 